\title{
Areeda-Turner in Two-Sided Markets
}

\author{
Stefan Behringer ${ }^{1} \cdot$ Lapo Filistrucchi $^{2,3}$
}

(C) The Author(s) 2015. This article is published with open access at Springerlink.com

\begin{abstract}
We extend the Areeda-Turner rule to two-sided markets. We show that a two-sided monopolist may find it short-run profit-maximizing to charge a price below marginal cost on one side of the market. Hence showing that the price is below marginal cost on one side of a two-sided market cannot be considered a sign of predation. We then argue for a two-sided Areeda-Turner rule that takes into account price-cost margins on both sides of the market. Two examples highlight that applying a one-sided Areeda-Turner rule may lead one to assess legitimate prices as predatory or to consider predatory prices as legitimate.
\end{abstract}

Keywords Daily newspapers - Market definition - Network effects - Predation · Two-sided markets

JEL Classification $\mathrm{L} 12 \cdot \mathrm{L} 41 \cdot \mathrm{L} 82$

Lapo Filistrucchi

lapo.filistrucchi@unifi.it

Stefan Behringer

stefan.behringer@uni-due.de

1 Mercator School of Management, Universität Duisburg-Essen, LS Allgemeine Volkswirtschaftslehre, Lotharstrasse 65, 47057 Duisburg, Germany

2 Department of Economics and Management, University of Florence, Via delle Pandette 9, 50127 Florence, Italy

3 CentER and TILEC, Tilburg University, Tilburg, The Netherlands 


\section{Introduction}

In this paper, we extend the Areeda-Turner rule to two-sided markets. We do so by following the original logic of Areeda and Turner (1975). In their seminal article, the authors set out to identify a rational dividing line between legitimately competitive prices and prices that should be regarded as predatory. Adopting the classical definition of predation as the deliberate sacrifice of present revenues for the purpose of driving rivals out of the market and then recouping the losses, they proposed that " $[\mathrm{u}]$ nless at or above average cost, a price below reasonably anticipated (1) shortrun marginal costs or (2) average variable costs should be deemed predatory, and the monopolist may not defend on the grounds that his price was 'promotional' or merely met an equally low price of a competitor". In addition "[r]ecognizing that marginal cost data are typically unavailable" they concluded that "[a] price below reasonably anticipated average variable cost should be conclusively presumed unlawful". 1

Following the original logic of Areeda and Turner (1975), we seek a threshold for the price, such that a price below this threshold should be deemed predatory. We argue that such a threshold needs to take into account the specificity of two-sided markets. In these markets firms act as platforms and sell two different products or services to two distinct groups of customers. ${ }^{2}$ An example is the newspaper market, in which publishers sell content to readers and advertising slots to advertisers.

A two-sided market is further characterised by indirect network externalities between the two groups of users. These arise when the utility (or the profits) obtained by a customer (whether a final consumer or a firm) of one group depends on the number of customers of the other group and the two groups of customers do not internalise these externalities. ${ }^{3}$

In the case of newspapers, advertisers place a greater value on advertising in a given newspaper the more readers the newspaper has. Readers may or may not be affected by the amount of advertising in the newspaper, ${ }^{4}$ but for the market to be two-sided already the presence of one indirect network effect is sufficient. ${ }^{5}$

Whereas customers do not internalize the externality (or externalities) above, two-sided platforms do internalize it (them) when deciding their optimal pricing

\footnotetext{
${ }^{1}$ Areeda and Turner (1975, p. 733).

2 See Caillaud and Jullien (2001, 2003), Rochet and Tirole (2002, 2003, 2006), Evans (2003), Parker and Alstyne (2005) and Armstrong (2006).

${ }^{3}$ As a result, a two-sided platform is different from a firm that sells complementary products. Indeed in the latter case there is only one group of customers who typically buy both goods (e.g. the ink-jet printer and the ink-jet cartridge) and thus, unless they are naive, they respond to changes in the prices of both. In a newspaper market, instead, a reader does not care about the price charged to advertisers and vice versa advertisers do not decide whether to place an ad in a newspaper based on the cover price of the latter.

${ }^{4}$ Empirical evidence so far seems to suggest that on average readers of daily newspapers are either indifferent to or slightly like advertising (which is usually not targeted but avoidable). See Argentesi and Filistrucchi (2007), Fan (2013) and Filistrucchi et al. (2012). Readers of magazines seem instead to attach a positive value to advertising (which is avoidable and more targeted). See Kaiser and Wright (2006) and Kaiser and Song (2009).

${ }^{5}$ See Filistrucchi et al. (2013).
} 
strategies. As a result, the profit-maximizing prices by two-sided platforms may be very different from those charged by firms in one-sided markets.

As pointed out by Rochet and Tirole (2006), in a two-sided market, where two products or services are sold to two groups of customers, one can distinguish the price level from the price structure. The price level is the sum of the two prices, while the price structure is the ratio of the two prices. When the unit of measurement of the goods or services sold on the two-sides are different and the matching of customers on the two sides is not one to one, the price level is not simply the sum of the two prices, but rather the sum of the two prices expressed in the same unit of measurement.

In the case of newspapers the price level is the sum of the cover price and the percopy advertising revenues. ${ }^{6}$ Similarly, the price structure is the ratio of the two. ${ }^{7}$ In two-sided markets not only the price level but also the price structure determines firms' profits. For instance, the profits of a publisher not only depend on how much revenues per copy of the newspaper it can raise but also on what percentage of revenues comes from readers versus advertisers: For a given revenue per copy, a business strategy that charges only readers may not be as profitable as one that charges only advertisers. Indeed, we observe free newspapers more often than we observe no-advertising newspapers.

The difference in pricing strategies that characterizes two-sided markets warrants in many instances a different antitrust treatment. A recent review discussing these issues is Evans and Schmalensee (2015).

Parker and Alstyne (2005) were among the first to present an economic model that highlights that in two-sided markets pricing below marginal cost on one side may be a (nonstrategic) profit-maximising strategy. Indeed, by pricing below marginal cost on one side of the market a firm increases sales on that side, thus boosting demand and profits on the other side. Wright (2004) included the claim that "price below marginal cost on one side of the market is a sign of predation" among the eight fallacies that derive from applying a one-sided logic to two-sided markets. ${ }^{8}$

Despite the warnings of the economics literature, competition authorities and courts tend to analyse predatory claims with a one-sided logic. In the recent case Bottin Cartographes versus Google, ${ }^{9}$ for instance, the Commercial Court of Paris

\footnotetext{
${ }^{6}$ One can also express the price level in terms of advertising pages. In that case it is the sum of the advertising price and the circulation revenues per-advertising-page.

7 Note that such a ratio is equivalent to the ratio between the revenues from the two sides. In the newspapers' business the ratio of circulation revenues to advertising revenues (or vice versa) is sometimes called the 'financing mix'.

8 To our knowledge, no paper discusses the conditions for predation in prices to take place in a two-sided market. A partial exception is Motta and Vasconcelos (2012) who present a model of platform competition in which below-cost pricing can be used to deter the entry of a more efficient rival. However, the result in Motta and Vasconcelos (2012) crucially depends on the fact that one of the two firms is already present in the market, while the other is trying to enter.

9 Bottin Cartographes v. Google Inc. and Google France Srl, Commercial Court of Paris, 15th chamber, 31 January 2012, available at http://www.legalis.net/spip.php?page=jurisprudence-decision\&id_article= 3327. In July 2009 Bottin Cartographes SAS (hereafter 'Bottin') filed a lawsuit before the Commercial Court of Paris (Paris Tribunal de Commerce) against Google Inc. and Google France Srl (hereinafter collectively 'Google') for alleged abuse of a dominant position in the market of online mapping services
} 
found Google guilty of the abuse of a dominant position in the market for online maps that allow stores' geolocation. ${ }^{10}$ The Court reached its decision by simply considering that the price of Google Maps API, being equal to $0 €$, was necessarily lower than the production costs of the service. Interestingly, the Court stopped just short of recognizing the implications for competition policy of the two-sided business strategy of Google, as it recognized that Google, according to the contracts, would be able to insert advertising in its Google Maps API service and therefore sell targeted advertising.

Judgements such as the one above may partly be due to the fact that most policy contributions so far, such as Wright (2004), have criticized the application of the one-sided Areeda-Turner rule to two-sided markets without suggesting an alternative. Even those policy contributions, such as Fletcher (2007) or Evans and Noel (2008), that recognized the necessity to provide guidance to practitioners fall short of providing new applicable methods. In fact, when Google appealed the decision of the Commercial Court of Paris, the Court of Appeal of Paris ${ }^{11}$ decided to suspend the proceeding and ask the French Competition Authority to deliver an opinion on whether Google's conduct had to be considered anticompetitive. ${ }^{12}$ The request of the Court of Appeal highlights the uncertainty among practitioners with regard to criteria to establish predatory pricing in two-sided markets.

We contribute to filling this gap by explaining how one should modify the Areeda-Turner rule to account for the two-sidedness of a market. Testing for predatory pricing in a two-sided market must take into account the presence of the indirect network effects between the two sides. Hence, it has to recognize that pricecost margins on the two sides of the market are interrelated. We thus show that one needs to compare the overall price level with the joint marginal cost of the two-sides of the market. Since, as already noted by Areeda and Turner (1975), marginal cost data are difficult to obtain, one should compare the overall price level with the overall average variable cost.

Footnote 9 continued

that provide stores' geolocation on firms' websites. Bottin is a multimedia mapping company that provides, among other things, online map applications that allow users to locate addresses and create itineraries online, which compete in France with the equivalent service of Google Maps API (Application Programming Interface). While Bottin offers its service in exchange for an annual fee and an ex post compensation based on actual consumption, the ordinary version of Google Maps API is provided to its customers on a free basis. Bottin claimed that this had to be considered a predatory pricing and that by doing so Google aimed to extend its dominant position in the market of online search to the connected relevant market.

${ }^{10}$ More precisely, with its decision of 31 January 2012 the Commercial Court of Paris found Google guilty of the abuse of a dominant position pursuant to Article L-420-2 paragraph 1 of the French Commercial Code and, as a consequence, awarded Bottin 500,000€ damages and interests, in addition to ordering Google to publish the judgment at its expense in several French and international newspapers.

11 Bottin Cartographes v. Google France and Google Inc. Court of Appeal of Paris, 5th Pole, 5th Chamber, 20 November 2013, available on http://www.legalis.net/spip.php?page=jurisprudencedecision\&id_article $=3942$.

12 The opinion of the Competition Authority has not been made public yet. In fact, it can be disclosed only after the ruling of the Appeal Court (art. L.462-3 of the French Code of Commerce), which has not been handed out yet. 
Filistrucchi et al. (2013) point out that there exist two-types of two-sided markets. Two-sided non-transaction markets are characterized by the absence of a transaction between the two sides of the market and, even though an interaction is present, it is usually not observable, so that a per-transaction (or per-interaction) fee or a two-part tariff is not possible. Typical examples are media markets. Two-sided transaction markets are instead characterized by the presence and observability of a transaction between the two groups of platform users. As a result, the platform is able to charge not only a price for joining the platform, but also one for using it, i.e. it can ask a two-part tariff. Examples in this category include payment cards schemes, virtual marketplaces, auction houses and operating systems.

The extension of the Areeda-Turner rule that we develop is in line with the suggestion by Evans (2003) for transaction markets. ${ }^{13}$ This suggestion was however not derived from a formal model. In addition, Evans (2003) recognized the difficulty in providing guidance as to how to implement the test in two-sided non-transaction markets. Our formulas, which are derived from the application of the same logic as Areeda and Turner (1975), are applicable instead to two-sided non-transaction markets, such as the market for newspapers that we consider in Sect. 3. However, following the same approach also for two-sided transaction markets, one would indeed obtain similar formulas to those proposed by Evans (2003).

Discussing predatory pricing in two-sided transaction markets, Fletcher (2007) suggested that a predatory pricing rule should be drawn from the finding in Rochet and Tirole (2006) that the markup on each side of a two-sided market can be calculated as in a one-sided market, with the caveat that from the marginal cost one needs to subtract any extra revenue that the extra sales on that side of the market generate on the other side of the market. It turns out that the latter intuition is, to some extent, true also for two-sided non-transaction markets. By deriving our conditions from a formal model, we explain what this extra term is in a two-sided non-transaction market and highlight that one also needs to take into account the extra cost incurred on the other side of the market.

We then apply our two-sided Areeda-Turner rule to two cases in the newspaper industry. We first look at the price war in the UK quality daily newspapers in the '90s and test whether the pricing strategy of The Times from September 1993 to December 1995 was an example of predatory pricing, as claimed by its competitors, particularly by the Independent. The case was investigated by the Office of Fair Trading (OFT) which concluded against the existence of predatory behaviour.

The case enjoyed considerable publicity at the time for its political implications and has not ceased to be debated, not only because the OFT decision, whether right or wrong, did not include much empirical investigation but also because, looking at it today in light of the theory of two-sided markets, it is striking that the OFT did not carry out any analysis of the advertising market. We show that, had it done so, it would have found that the pricing strategy of the Times was probably not predatory, even taking for granted the cost estimates of The Independent, according to which the Times was sold to readers at a price below average variable cost.

13 Evans (2003) calls them 'matchmaking' two-sided markets. 
We then discuss the case of Aberdeen Journals, whose pricing strategies between 1996 and 2000 were also investigated by the OFT. It was a case of alleged predation that involved free newspapers in Scotland. The OFT and the Competition Appeal Tribunal (CAT) calculated price-cost margins and concluded that the advertising prices that were set by Aberdeen Journals in response to the entry of Aberdeen \& District Independent were below average variable costs and, therefore, predatory. We argue that, although readers did not pay for the newspapers, the OFT took the right approach in taking into account also the costs incurred on the readers side.

The paper is organised as follows: Sect. 2 compares monopoly pricing in twosided markets to monopoly pricing in one-sided markets and extends the one-sided Areeda-Turner rule to two-sided markets. In Sect. 3 we analyse the two cases of alleged predatory behaviour in the market for daily newspapers, namely the Times versus Independent war and the Aberdeen Journals case. Section 4 concludes.

\section{Areeda-Turner from One to Two Sides}

\subsection{One-Sided Versus Two-Sided Monopoly Pricing}

We here show the difference between monopoly pricing in one-sided and two-sided markets.

Our starting point is the well-known formula for the mark-up in a one-sided monopoly

$$
\frac{\left(P-\frac{\partial C}{\partial Q}\right)}{P}=\frac{1}{\left|\eta_{P}^{Q}\right|}
$$

where $C(\cdot)$ is the monopolist's cost function and $\eta_{P}^{Q}$ is the elasticity of market demand $Q$ with respect to the price $P$.

This formula reminds us that a short-run profit-maximizing monopolist in a onesided market will set a price above marginal cost.

A monopolist in a two-sided market sets $P^{A}$ on side A of the market and $P^{R}$ on side $\mathrm{R}$ of the market ${ }^{14}$ so as to maximize overall profits

$$
\pi=P^{A} Q^{A}+P^{R} Q^{R}-C\left(Q^{A}, Q^{R}\right)
$$

subject to the constraints

$$
\begin{aligned}
& Q^{R}=Q^{R}\left(P^{R}, Q^{A}\right) \\
& Q^{A}=Q^{A}\left(P^{A}, Q^{R}\right)
\end{aligned}
$$

where the demands $Q^{R}(\cdot)$ and $Q^{A}(\cdot)$ are functions of prices on the same market side and of quantities on the other side of the market.

\footnotetext{
14 Our empirical examples below are for the daily newspaper market. Hence, we denote the two sides of the market with A (for advertisers) and $\mathrm{R}$ (for readers).
} 
In two-sided markets, quantities on one market side are functions of prices on that market side and quantities on the other market side. In the context of the newspaper industry, this means that the amount of advertising demanded is a function of the advertising price and the number of readers, while the number of readers is a function of the cover price and the quantity of advertising.

Filistrucchi and Klein (2013) show that if

$$
\left|\frac{\partial Q^{A}}{\partial Q^{R}} \frac{\partial Q^{R}}{\partial Q^{A}}\right|\left(1 \vee P^{A}, P^{R}\right)
$$

i.e. if the product of the indirect network effects is not too large, ${ }^{15}$ the users' coordination game, identified by Armstrong (2006) and further discussed by Weyl (2010), has a unique solution and the set of constraints can be rewritten as

$$
\begin{aligned}
& Q^{R}=\hat{Q}^{R}\left(P^{R}, P^{A}\right) \\
& Q^{A}=\hat{Q}^{A}\left(P^{A}, P^{R}\right)
\end{aligned}
$$

where the demands $\hat{Q}^{R}(\cdot)$ and $\hat{Q}^{A}(\cdot)$ are now functions of prices on both market sides only.

In other words, if the condition above holds, although customers do not internalize the link between demands, there exist reduced form demands which depend on prices on the two sides of the market. In the context of the newspaper market, it implies that it is possible to express both advertising demand and readership demands as functions of the advertising price and the newspaper price. ${ }^{16}$ Intuitively, this means that, given a set of prices chosen by the platform, there is only one set of quantities: the consumers coordination game, due to the fact that optimal decisions of customers on side A depend on decisions of customers on side $\mathrm{R}$ and vice versa, has a unique equilibrium.

Substituting (5) into the profit function above, one obtains

$$
\pi=P^{A} \hat{Q}^{A}\left(P^{A}, P^{R}\right)+P^{R} \hat{Q}^{R}\left(P^{R}, P^{A}\right)-C\left(\hat{Q}^{A}\left(P^{A}, P^{R}\right), \hat{Q}^{R}\left(P^{R}, P^{A}\right)\right)
$$

Then, the monopolist's profit maximizing prices solve the first order conditions

$$
\begin{aligned}
& \hat{Q}^{A}+\left(P^{A}-\frac{\partial C^{A}}{\partial \hat{Q}^{A}}\right) \frac{\partial \hat{Q}^{A}}{\partial P^{A}}+\left(P^{R}-\frac{\partial C^{R}}{\partial \hat{Q}^{R}}\right) \frac{\partial \hat{Q}^{R}}{\partial P^{A}}=0 \\
& \hat{Q}^{R}+\left(P^{A}-\frac{\partial C^{A}}{\partial \hat{Q}^{A}}\right) \frac{\partial \hat{Q}^{A}}{\partial P^{R}}+\left(P^{R}-\frac{\partial C^{R}}{\partial \hat{Q}^{R}}\right) \frac{\partial \hat{Q}^{R}}{\partial P^{R}}=0
\end{aligned}
$$

Filistrucchi and Klein (2013) show that one can obtain the derivatives of the reduced

\footnotetext{
15 In the newspaper example, consider the case of one more reader buying the (monopolist) newspaper. This starts a loop: more readers, more advertising, fewer readers, less advertising, more readers... and so on. Intuitively the condition above ensures that this loop converges for any set of prices. If so, when the publisher changes one price, the resulting change in quantities is finite.

16 This result is used in Affeldt et al. (2013) to derive formulas for Upward Pricing Pressure in a twosided market. An equivalent condition for two-sided markets is assumed to hold in Kaiser and Wright (2006) who bring the Hotelling model of Armstrong (2006) to the data.
} 
form demands from the derivatives of the original demands using the implicit function theorem: ${ }^{17}$

$$
\left(\begin{array}{ll}
\frac{\partial \hat{Q}^{A}}{\partial P^{A}} & \frac{\partial \hat{Q}^{A}}{\partial P^{R}} \\
\frac{\partial \hat{Q}^{R}}{\partial P^{A}} & \frac{\partial \hat{Q}^{R}}{\partial P^{R}}
\end{array}\right)=\frac{1}{d}\left(\begin{array}{cc}
\frac{\partial Q^{A}}{\partial P^{A}} & \frac{\partial Q^{A}}{\partial Q^{R}} \frac{\partial Q^{R}}{\partial P^{R}} \\
\frac{\partial Q^{R}}{\partial Q^{A}} \frac{\partial Q^{A}}{\partial P^{A}} & \frac{\partial Q^{R}}{\partial P^{R}}
\end{array}\right)
$$

where $d=1-\frac{\partial Q^{A}}{\partial Q^{R}} \frac{\partial Q^{R}}{\partial Q^{A}}>0$. Note that the sign of the cross-price derivatives depends on the sign of the network effects: If the network effect is positive, the cross-price derivative is negative, if the network effect is negative the cross-price derivative is positive.

From the first-order conditions in (2) and (3), one can obtain the monopolist's markup on each side of the market

$$
\begin{aligned}
& \left(\frac{P^{A}-\frac{\partial C}{\partial \hat{Q}^{A}}}{P^{A}}\right)=\frac{1}{\left|\eta_{P^{A}}^{\hat{Q}^{A}}\right|}+\left(\frac{P^{R}-\frac{\partial C}{\partial \hat{Q}^{R}}}{P^{R}}\right) \frac{R^{R}}{R^{A}} \frac{\eta_{P^{A}}^{\hat{Q}^{R}}}{\left|\eta_{P^{A}}^{\hat{Q}^{A}}\right|} \\
& \left(\frac{P^{R}-\frac{\partial C}{\partial \hat{Q}^{R}}}{P^{R}}\right)=\frac{1}{\left|\eta_{P^{R}}\right|}+\left(\frac{P^{A}-\frac{\partial C}{\partial \hat{Q}^{A}}}{P^{A}}\right) \frac{R^{A}}{R^{R}} \frac{\eta_{P^{R}}^{\hat{Q}^{A}}}{\left|\hat{Q}_{P^{R}}\right|}
\end{aligned}
$$

where $R^{R}$ are revenues from readers, $R^{A}$ are revenues from advertisers, $\eta_{P^{A}}^{\hat{Q}^{A}}$ is the total own-price elasticity on the advertisers' side, $\eta_{P^{R}}^{\hat{Q}^{R}}$ is the total own-price elasticity on the readers' side, while $\eta_{P^{R}}^{\hat{Q}^{4}}$ and $\eta_{P^{A}}^{\hat{Q}^{R}}$ are the total cross-price elasticities.

To understand these total elasticities, note that the total elasticity $\eta_{P^{R}}^{\hat{Q}^{R}}$ includes, in addition to the changes in $Q^{R}$ directly due to the change in $P^{R}$, also the additional changes in $Q^{R}$ due to the indirect network effects. Consider the newspaper example: Suppose that the monopolist increases the price to the readers $P^{R}$ while keeping the price to the advertisers $P^{A}$ unchanged; as a result the quantity of readers $Q^{R}$ decreases. This effect would be captured by a direct (or partial) elasticity $\eta_{P^{R}}^{Q^{R}}$. However, the decrease in the number of readers $Q^{R}$ also decreases the quantity of advertising sold $Q^{A}$ (as advertisers willingness to pay for an advertising slot in a newspaper increases with the number of readers). In turn, the decrease in advertising sold $Q^{A}$ increases the quantity of readers $Q^{R}$ (if readers of newspapers are annoyed by advertising), and so on. A similar reasoning applies to the total elasticities $\eta_{P^{R}}^{\hat{Q}^{A}}$ ,$\eta_{P^{A}}^{\hat{Q}^{R}}$ and $\eta_{P^{A}}^{\hat{Q}^{A}}$, which measure the effects of an increase in $P^{R}$ on $Q^{A}$ and of $P^{A}$ on $Q^{R}$ and on $Q^{A}$.

\footnotetext{
17 This is done also in Affeldt et al. (2013) to estimate the diversion ratios necessary to apply Upward Pricing Pressure in a two-sided market.
} 
From (9) one can check that the total own-price elasticities, $\eta_{P^{R}}^{\hat{Q}^{R}}$ and $\eta_{P^{A}}^{\hat{Q}^{A}}$, are negative when the condition for the existence of the reduced form demand functions is satisfied (i.e. when (4) holds). As a result, the first term on the right hand side, in both Eqs. (10) and (11), is positive. In both cases it resembles the term on the right hand side in the Eq. (1), but differs in that the elasticities in Eqs. (10) and (11) include the indirect network effects.

The existence of a second term on the right hand side, in both Eqs. (10) and (11), is also due to the presence of the indirect network effects. Its sign depends on the sign of total cross-price elasticities with respect to the readers' price and the advertisers' price ( $\eta_{P^{R}}^{\hat{Q}^{A}}$ and $\eta_{P^{A}}^{\hat{Q}^{R}}$ respectively) and on the sign of the markup on the other side of the market (either $\left(\frac{P^{R}-\frac{\partial C}{\partial \hat{Q}^{R}}}{P^{R}}\right)$ or $\left(\frac{P^{A}-\frac{\partial C}{\partial Q^{A}}}{P^{A}}\right)$ ). Hence, the markups on the two-sides of the market are interrelated.

Turning to total cross-price elasticities $\eta_{P^{R}}^{\hat{Q}^{A}}$ and $\eta_{P^{A}}^{\hat{Q}^{R}}$, they can be positive or negative, depending on the sign of the total derivatives $\frac{\partial \hat{Q}^{A}}{\partial P^{R}}$ and $\frac{\partial \hat{Q}^{R}}{\partial P^{A}}$ respectively, which in turn depend on the signs of the indirect network effects $\frac{\partial Q^{A}}{\partial Q^{R}}$ and $\frac{\partial Q^{R}}{\partial Q^{A}}$, as shown in Eq. (9).

Without loss of generality, let us consider the markup on side $\mathrm{R}$ given by Eq. (11). Substituting (10) into (11), one obtains

$$
\left(\frac{P^{R}-\frac{\partial C}{\partial \hat{Q}^{R}}}{P^{R}}\right)=\frac{\left|\eta_{P^{A}}^{\hat{Q}^{A}}\right|+\frac{R^{A}}{R^{R}} \eta_{P^{R}}^{\hat{Q}^{A}}}{\left|\eta_{P^{A}}^{\hat{Q}^{A}}\right|\left|\eta_{P^{R}}^{\hat{Q}^{R}}\right|-\eta_{P^{A}}^{\hat{Q}^{R}} \eta_{P^{R}}^{\hat{Q}^{A}}}
$$

where the denominator is positive because of assumption (4).

Assume $\eta_{P^{R}}^{\hat{Q}^{4}}<0$. This implies that customers on side A attach a positive value to customers on side R. ${ }^{18}$ Then the mark-up on side $\mathrm{R}$ is negative if

$$
\left|\eta_{P^{A}}^{\hat{Q}^{A}}\right|<\frac{R^{A}}{R^{R}}\left|\eta_{P^{R}}^{\hat{Q}^{A}}\right|
$$

i.e. if the total elasticity of $\hat{Q}^{A}$ with respect to $P^{R}$ is (sufficiently) larger than the total elasticity of $\hat{Q}^{A}$ with respect to $P^{A}$ and revenues from side A are more important then revenues from side $\mathrm{R}$. In this case, it is more profitable to lower the price to customers on side $\mathrm{R}$ and increase the price to customers on side $\mathrm{A}$.

We have thus shown that, depending on the sign and size of the own-price effects and the indirect network effects, it may be a short-run profit maximizing strategy for a monopolist in a two-sided market to set a price below marginal cost on one side of the market. In the context of our newspaper example, it may be the case that a monopolist publisher finds it privately optimal to distribute its newspaper for free to readers (even though there are marginal production and distribution costs) while selling advertising space to advertisers.

\footnotetext{
18 This too is without loss of generality, because in a two-sided market customers of at least one side must attach a positive value to customers of the other side.
} 


\subsection{A Two-Sided Areeda-Turner Rule}

Given that a monopolist might find it profit maximizing in the short-run to set a price below marginal cost on one side of a two-sided market, setting a price below marginal cost on one side only cannot be considered a sign of predation. Hence, as claimed also by Evans (2003) and Wright (2004), the Areeda-Turner rule cannot be applied to only one side of a two-sided market. One needs instead to apply the logic of Areeda and Turner (1975) to two-sided markets.

Clearly a possibility for a two-sided Areeda-Turner rule would be to require that both prices be below their respective marginal costs for the pricing strategy of a dominant firm to be presumed predatory. However, this would restrict the set of prices found to be predatory more than the Areeda-Turner rule does in one-sided markets.

In such markets, the benchmark is a price that is equal to marginal cost. Any lower price implies that the monopolist is making a loss at the margin, while economic theory predicts that a profit-maximizing monopolist will make a gain at the margin. In addition, if marginal costs are constant, any price that is lower than marginal cost also implies that the monoplolist is making negative variable profits.

The benchmark should be the same in two-sided markets: Prices such that the monopolist is making an overall loss at the margin should be considered predatory. For such prices it should also be the case that, if marginal costs are constant, a monopolist makes negative profits. Instead, if the criterion is that the price should be below marginal cost on both sides of a two-sided market, this would consider as non-predatory a substantial set of prices at which a monopolist is making an overall loss at the margin: all of those prices for which the monopolist makes a marginal gain on one side and a marginal loss on the other side but the latter overwhelms the former.

To see this, consider the case in which the monopolist is making a loss on side $\mathrm{R}$, i.e. $P^{R}-\frac{\partial C}{\partial \hat{Q}^{R}}<0$. Then, for the monopolist to make a loss overall, it is not necessary that it also makes a loss at the margin on side A, i.e. it is not necessary that $P^{A}-\frac{\partial C}{\partial \hat{Q}^{A}}<0$. Instead it is necessary that the marginal gain on side $\mathrm{A}$ is not enough to offset the marginal loss on side $\mathrm{R}$. The same holds, of course, if $\mathrm{R}$ and $\mathrm{A}$ are reversed Thus, an Areeda-Turner rule for two-sided markets, would specify that prices on side $\mathrm{R}$ should be considered predatory if

$$
\left(P^{R}-\frac{\partial C}{\partial \hat{Q}^{R}}\right)+\left(P^{A}-\frac{\partial C}{\partial \hat{Q}^{A}}\right) \frac{\partial Q^{A}}{\partial Q^{R}}<0
$$

while prices on side A should be considered predatory if

$$
\left(P^{A}-\frac{\partial C}{\partial \hat{Q}^{A}}\right)+\left(P^{R}-\frac{\partial C}{\partial \hat{Q}^{R}}\right) \frac{\partial Q^{R}}{\partial Q^{A}}<0
$$

In other words, for a two-sided market one can reformulate the Areeda-Turner rule as follows: 
When the sum of the prices on the two-sided market, weighted by the marginal network effect, is lower than the sum of the corresponding marginal costs, weighted by the marginal network effect, prices should be judged predatory.

Conditions (14) and (15) imply not only that the profit margin on one side should be negative but also that the weighted sum of the profit margins on the two-sides should be negative, when the appropriate network effect is taken as the weight. Hence, a finding of negative profit margins on both sides would be sufficient to justify a presumption of predatory pricing in the Areeda-Turner spirit, but it would not be necessary.

In fact, there is no guarantee that the profit margin on a given side is positive, even for a profit maximizing monopolist: From the first order conditions (7) and (8), using (9) to substitute for the derivatives, one obtains

$$
\begin{aligned}
& \left(P^{R}-\frac{\partial C^{R}}{\partial \hat{Q}^{R}}\right)+\left(P^{A}-\frac{\partial C^{A}}{\partial \hat{Q}^{A}}\right) \frac{\partial Q^{A}}{\partial Q^{R}}=-\frac{\hat{Q}^{R}}{\partial \hat{Q}^{R} / \partial P^{R}}>0 \\
& \left(P^{A}-\frac{\partial C^{A}}{\partial \hat{Q}^{A}}\right)+\left(P^{R}-\frac{\partial C^{R}}{\partial \hat{Q}^{R}}\right) \frac{\partial Q^{R}}{\partial Q^{A}}=-\frac{\hat{Q}^{A}}{\partial \hat{Q}^{A} / \partial P^{A}}>0
\end{aligned}
$$

These conditions show that for a profit-maximizing monopolist the weighted sum of the profit margins in (14) and (15) would be positive. As argued above, for such a monopolist on at least one side of the market the profit margin must be positive, but on the other side it could be negative. Conditions (15) and (14) also ensure that predatory prices are such that variable profits are negative if average variable costs are constant.

Finally, recognizing not only, as did Areeda and Turner (1975), that marginal cost data are typically unavailable, but also that estimates of the marginal network effect are not easy to obtain, prices should be presumed predatory if

$$
\left(P^{R}-A V C^{R}\right)+\frac{Q^{A}}{Q^{R}}\left(P^{A}-A V C^{A}\right)<0
$$

or, equivalently, ${ }^{19}$ if

$$
\left(P^{A}-A V C^{A}\right)+\frac{Q^{R}}{Q^{A}}\left(P^{R}-A V C^{R}\right)<0
$$

Note that these conditions preserve the properties that: a) the left-hand side is positive for a profit-maximizing monopolist; and b) if a set of prices satisfy it and marginal costs are constant, variable profits are negative. These same properties are preserved in a one-sided market when one uses $(P-A V C)<0$ instead of

\footnotetext{
19 Only in the special case in which one side does not affect the other, e.g. when readers do not care about the number of ads in the newspaper, condition (19) will become

$\left(P^{A}-A V C^{A}\right)<0$

while condition (18) will remain unchanged. In this case, they would not be equivalent.
} 
$\left(P-\frac{\partial Q}{\delta C}\right)<0$.

To conclude, for most practical purposes, for a two-sided market one can reformulate the Areeda-Turner rule as follows:

A (weighted) price level below the reasonably anticipated (weighted) average variable cost level should be judged predatory.

\section{An Application to Daily Newspapers}

To illustrate the results that were derived in the previous section, we now analyse two alleged cases of predatory pricing in the newspaper industry, which is a typical two-sided industry. The first case - the Times-Independent price war-highlights the importance of using the correct Areeda-Turner rule for two-sided markets rather than the one-sided rule and concerns the quality newspaper market, where both readers and advertisers pay to access the platform. The second-the Aberdeen Journals case-concerns the market for free newspapers and illustrates how one should deal with predatory allegations in those two-sided markets in which one side of the market does not pay. In fact, that customers on one side may not pay is a common feature of many two-sided markets, from the traditional free-to-air TV market to many recent online services (such as Internet search, online news, free email accounts and social networks).

\subsection{The Times: Independent Price War}

During the early 1990s the UK market for quality broadsheet newspapers had experienced stable cover prices. On the 1st September 1993, The Times, The Independent and The Guardian were priced at $45 \mathrm{p}$, and The Daily Telegraph was priced at $48 \mathrm{p}$.

On 6 September 1993 The Times lowered its price by $33 \%$, from 45 to $30 \mathrm{p}$. As its circulation revenues came under pressure, on 12 October 1993 The Independent raised its price from 45 to 50 p. On 23 June 1994, while The Daily Telegraph matched the new price of The Times (lowering its price by $37.5 \%$ ), The Independent was offered on a one-day sale for $20 \mathrm{p}$, with the following announcement appearing on its first page: "We remain dedicated to journalism of the highest quality and integrity. Readers will understand that this can never be cheap". On 24 June 1994 The Times lowered its price by another $33 \%$, from 30 to $20 \mathrm{p}$, bringing the overall price cut to $55 \%$. Finally, on 1 August 1994 The Independent was also forced to lower its price by $40 \%$, from 50 to $30 \mathrm{p}$. Figure 1 depicts this price war graphically. ${ }^{20}$

The Independent claimed to be the target of a predatory attempt by the Times. It held that the prices of 30 and 20 p per copy of The Times amounted respectively to a " $£ 18 \mathrm{~m}$ a year" and a "£30m a year" subsidy. It filed a complaint with the OFT. A 'deep pocket' predator story was put forward, according to which NIN (which

\footnotetext{
${ }^{20}$ Note that the graph reports average prices per month. Hence, unless the price change takes place on the first day of the month, the changes appear in the graph a bit smoother than one would expect given the description in the text.
} 


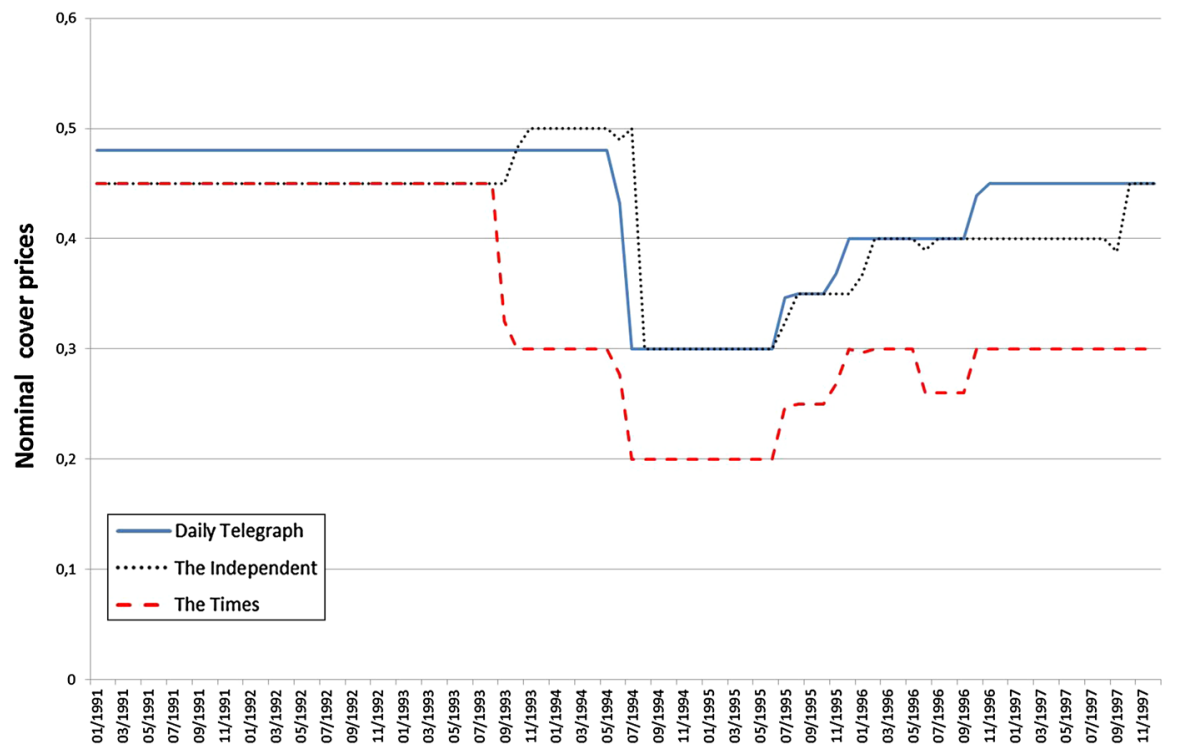

Fig. 1 The price war

owned The Times) could afford to sustain higher losses than could The Independent, thanks to cross-subsidization from other profitable media businesses that it owned.

The OFT investigations into the price cuts of September 1993 and June 2004 led to the conclusion that The Times was not dominant in The readers' market for national daily newspapers and that The Independent was just one of its competitors. Hence The Times could not reasonably expect that the losses that it would incur in the "predatory" campaign would be recouped by a higher price after The Independent would have exited the market. As a result the OFT dismissed the claims of predation.

The price war influenced the public discussion of the adoption of the new UK Competition Act in 1998: The House of Lords sought, without success, to introduce an amendment to the bill that would specifically prohibit predatory prices, even in the absence of a dominant position by the predator, in circumstances that might reduce the diversity of the press.

As also shown in Fig. 1, from July 1995 cover prices of The Times, The Daily Telegraph and The Independent started to rise, and from January 1996 they stabilized again.

However in 1998, following another formal complaint by The Daily Telegraph, The Guardian and The Independent, the OFT investigated The Times' behavior during the period between June 1996 and January 1998 when the Monday edition was sold for $10 \mathrm{p}$, and concluded that such prices were predatory. ${ }^{21}$

\footnotetext{
${ }^{21}$ Since, this behavior had ended 16 months before the end of the investigation, the OFT decided not to refer News International (publisher of The Times) to the Competition Commission for charges and accepted assurances given by the publisher that it would notify and provide detailed justification for any future reductions of its cover price.
} 
Interestingly, in all of its investigations, the OFT failed to recognize the twosidedness of the market and the fact that the losses from the readers' market might be covered by gains in the advertising market.

We draw on the data in Behringer and Filistrucchi (2011) to show that despite the huge cut in prices, the pricing strategy of The Times in 1993 and 1994 could not be presumed predatory according to the Areeda-Turner rule properly modified to take into account the two-sidedness of the market, i.e. according to Eq. (18). Behringer and Filistrucchi (2011) argue that the observed price war can be rationalized by the boom in the advertising market, which shifted the optimal business model of publishers towards more advertising financing.

In particular, on the readers' side of the market, we use monthly observations of circulation and cover prices. On the advertising side of the market we use monthly observations on advertising quantity and revenues of The Times. ${ }^{22}$ We recover advertising prices by dividing revenues by quantity. Our sample covers the period 1991-1997.

According to The Independent the average variable cost of the Times was $32.5 \mathrm{p}: 17.5 \mathrm{p}$ went to the distribution and the cost of printing a copy was $15 \mathrm{p}$. Since this was reported by the complainant, if anything the estimate should be biased upward and the resulting price-cost margins should be biased towards predation. We thus use this estimate (adjusting it by the monthly CPI) to estimate the overall markups of the Times from 1991 to 1997 per copy sold, taking into account both the cover price and the revenues from advertising as suggested by the two-sided Areeda-Tuner rule in (18). ${ }^{23}$ Figure 2 shows that, although the overall per copy markup of The Times dropped substantially during the price war, it always remained above zero. Clearly, with a marginal cost of $32.5 \mathrm{p}$ at a price of $30 \mathrm{p}$ or $20 \mathrm{p}$, the price-cost margin solely on the readers' side was negative. Applying the Areeda-Turner rule to the readers' side of the market only would lead to the conclusion that prices are predatory.

However, as shown by Fig. 3, the cut in prices led to a substantial increase in circulation. Figure 4 shows that the higher circulation led to an increase in advertising revenues. The latter effect is taken into account by a two-sided AreedaTurner rule, but not by a one-sided Areeda-Turner rule. This illustrates how they can lead to different conclusions.

\subsection{The Aberdeen Journals' Case}

While the case The Times versus Independent concerned alleged predation on the cover price in the market for national newspapers, the case of Aberdeen Journals concerned a case of alleged predation of the advertising price in the market for local

\footnotetext{
${ }^{22}$ Data on circulation come from those collected by the Audit Bureau of Circulation (ABC). Data on prices were collected from the newspaper publishers themselves. The advertising data were acquired from Nielsen Media Research UK.

23 Note that we consider all advertising costs to be fixed in the short-run. This assumption is in line with the outcome of the discussion, by market participants and the OFT, of newspaper costs in the Aberdeen Jounals's case. The rationale is that advertising staff is fixed in the short-run and that printing one page of content or one page of advertising has the same cost.
} 


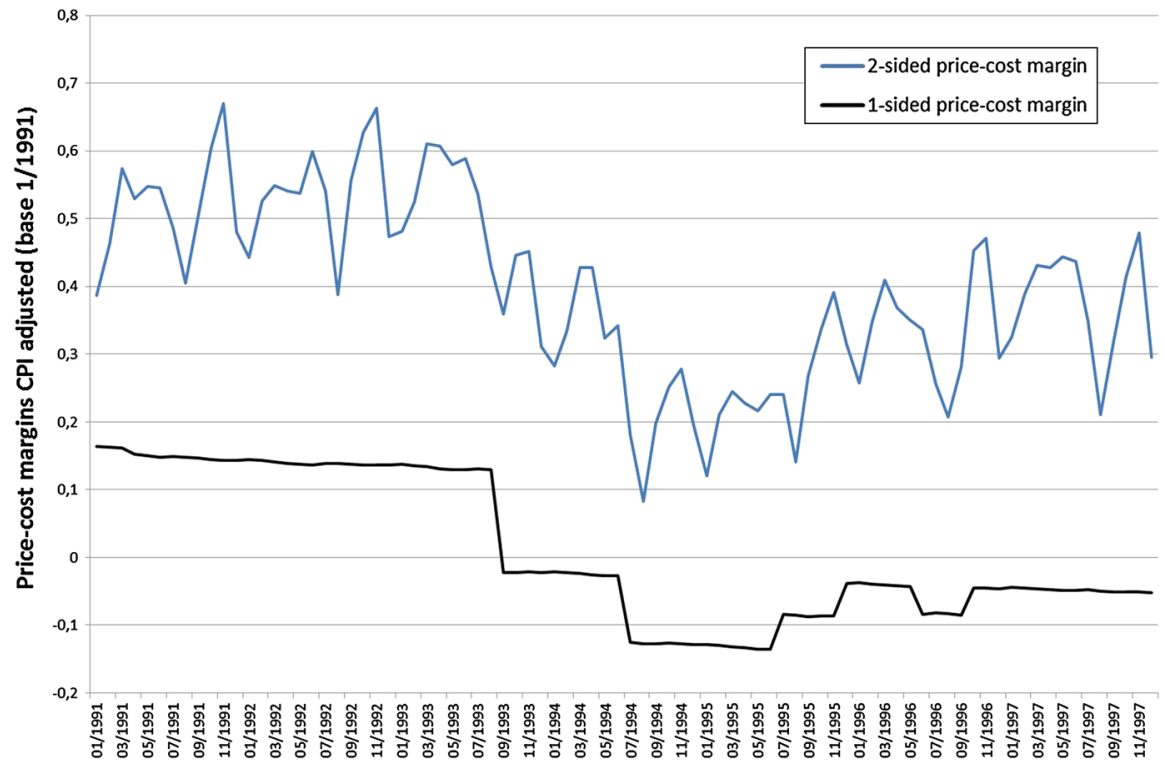

Fig. 2 Two-sided and one-sided price-cost margins for The Times

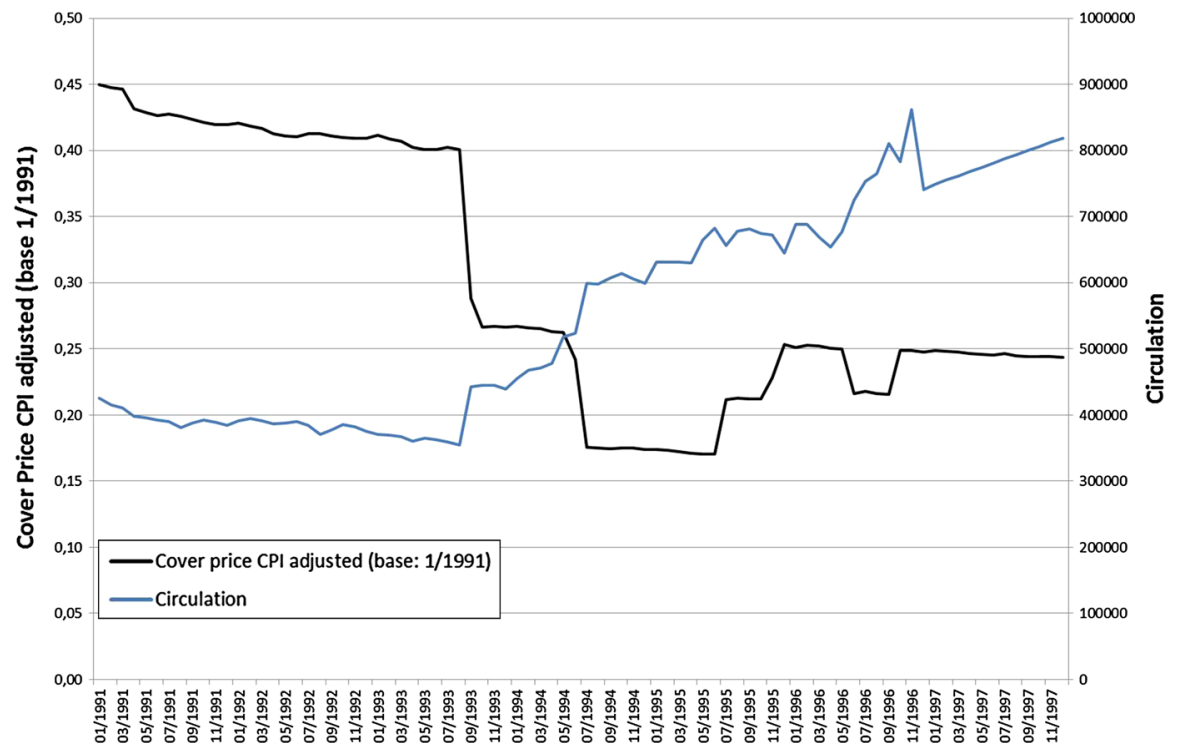

Fig. 3 Cover price and circulation of The Times

newspapers. More importantly, the case of Aberdeen Journals concerned a twosided market where one side did not pay, but, differently from the recent Bottin Cartographes versus Google case that we discussed in the introduction, the 


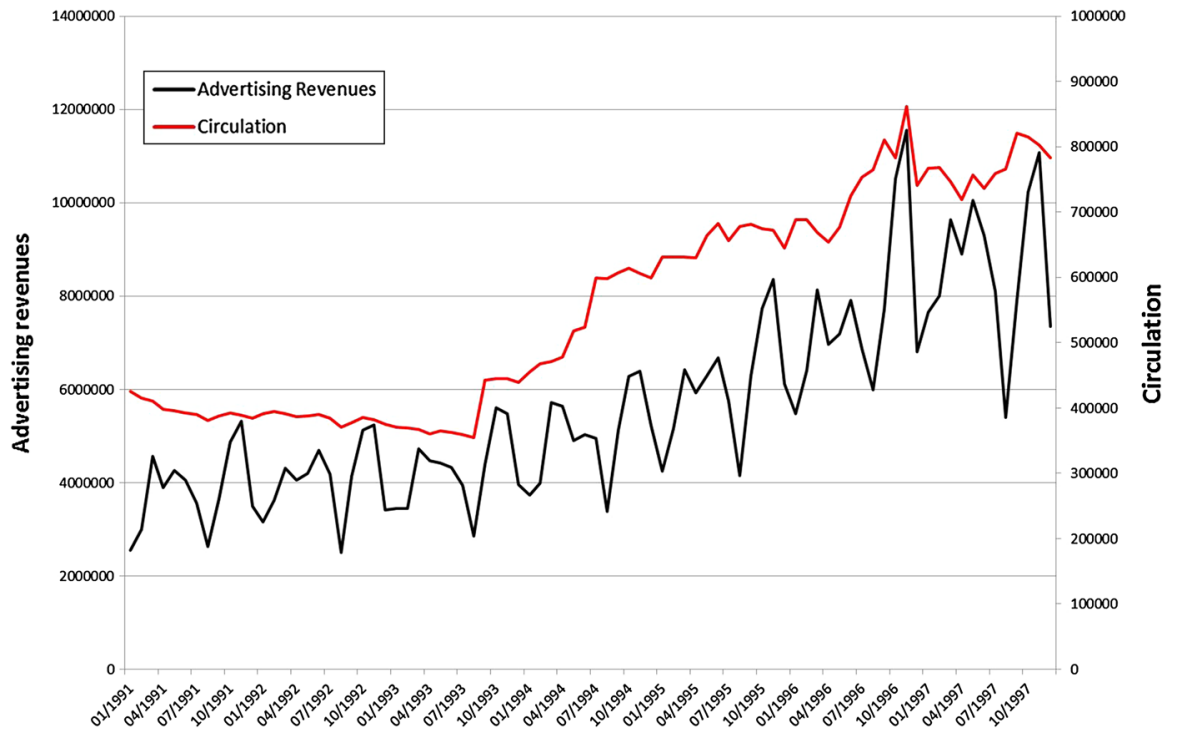

Fig. 4 Circulation and advertising revenues of The Times

allegations of predation referred to pricing on the paying side. This raises additional issues with regard to the application of the correct two-sided Areeda-Turner rule.

The case follows in time the Times-Independent price war that was discussed in the previous section. After the introduction of the UK Competition Act on 1 March 2000, which made the abuse of a dominant position illegal, Aberdeen \& District Independent complained that Aberdeen Journals Limited was engaging in predatory pricing of advertising space in its free newspaper Herald \& Post.

On 16 July 2001, and again on 29 September $2002,{ }^{24}$ the OFT issued its decision against the Aberdeen Journals, which was owned by Northcliffe Newspapers Group Ltd. The OFT found that Aberdeen Journals was dominant in the market for the supply of advertising space in local newspapers (paid-for and free) within the Aberdeen area. The OFT also concluded that Aberdeen Journals had engaged in predation against its only rival in the relevant market, the Aberdeen \& District Independent: it deliberately incurred losses on its free newspaper, the Herald \& Post, by pricing advertising space at below average variable cost in an attempt to exclude the Aberdeen \& District Independent. According to the OFT, predatory pricing started in response to the launch of the Aberdeen \& District Independent in 1996 and continued until 29 March 2000, 4 weeks after the Competition Act came into force.

\footnotetext{
${ }^{24}$ The OFT decision of 16 July 2001 was appealed to the Competition Commission Appeal Tribunal (CCAT), which set it aside on the basis that the market definition on which the decision had been made was inadequate. The OFT issued a new decision on 29 September 2002 confirming the original findings. The decision covers a period of infringement from the introduction of the Competition Act on 1 March 2000, which makes the abuse of a dominant position illegal, to 29 March 2000.
} 
In order to assess predation, the OFT conducted an empirical analysis that was aimed at establishing whether advertising revenues were higher than average variable costs. ${ }^{25}$ While the Herald \& Post did not incur losses prior to the entry of the Independent, it started to make losses in March 1996 after it heavily decreased advertising rates, increased pagination and increased circulation.

The average advertising rate was cut drastically shortly after the launch of the Aberdeen \& District Independent in April 2006. It was significantly cut again in October 1998 and the price remained below that level until July 1999. A significant rise took place only in April 2000. Also, the pagination, i.e. the number of pages per month, of the Herald \& Post was significantly increased following the launch of the Independent from under 100 pages per month in the period October 1995 to April 1996 to 148 pages in May 1996 and peaking between September 1998 and October 1999 when it was in the range of 350 to 480 pages a month. Lastly, the distribution of the Herald \& Post substantially increased after the entry of the Independent from below 100,000 to as much as 126,000 in 1999.

Importantly, the OFT always took into account the costs that were necessary to serve the readers even if readers did not pay for the product.The OFT noted that whether costs are fixed or variable depends also on the time frame. In particular, it carried out its analysis with reference to both a shorter time frame (the month) and a longer time frame (the alleged predation period). Clearly, considering a larger time frame implies considering more costs as variable and makes a finding of predation more likely. When taking the longer time horizon, the OFT included among variable costs the costs of printing, distribution, editorial staff (i.e. costs on the readers side) and advertising staff (i.e. costs on the advertising side). It thus estimated that The Herald \& Post was selling below average variable costs at least through March 2000. Furthermore, treating editorial staff and the advertising team as fixed and the cost of printing and distribution (i.e. only costs on the readers side) as variable, the OFT estimated that the Herald \& Post's revenues exceeded variable costs only on five occasions between July 1996 and March 2000.

Without access to the data, which were marked as confidential and thus not reported, we cannot check whether indeed the price that was charged by Aberdeen Journals was predatory. However, even without access to the data, based on the theoretical results in Sect. 2, we can claim that the OFT applied the correct twosided Areeda-Tuner rule when it took into account average variable costs related to both sides of the market. In fact, even if on one-side of the market the platform gives away the product for free, as it is the case with free newspapers, then one still needs to apply the two-sided Areeda-Turner rule given by Eq. (18). However, since on the readers' side of the market the newspaper was given away for free, Eq. (18) reduces to $P^{A}-A V C^{A}-\frac{Q^{R}}{Q^{A}} A V C^{R}<0$ when the OFT takes as a reference the longer time frame and to $P^{A}-\frac{Q^{R}}{Q^{A}} A V C^{R}<0$ when it chooses the shorter time horizon. ${ }^{26}$

\footnotetext{
${ }^{25}$ Internal memoranda also showed that the conduct was intentional and that the Herald \& Post was subsidized by its parent company Northcliffe Newspapers Group Ltd in order to drive the Aberdeen \& District Independent out of the market.

${ }^{26}$ This is because, according to the OFT, in the shorter time frame all advertising costs were fixed (as they were mostly related to advertising staff).
} 
In other words, although one side of the market does not pay for the product it receives (e.g. here readers do not pay for a copy of the newspaper), still the average variable costs to serve that side of the market need to be taken into account to assess predation. ${ }^{27}$ Otherwise, one would run the risk of not sanctioning platforms that charge predatory prices consistent with the logic of Areeda and Turner (1975).

\section{Conclusion}

In their seminal paper, Areeda and Turner (1975) argued that a price below marginal cost should be considered a sign of predation. Recognizing that marginal cost data were typically unavailable, the authors suggested to presume as unlawful a price that is below average variable cost. This Areeda-Turner rule has become the conceptual reference to assess claims of predation. Different authors have highlighted possible short-comings of the rule, while different jurisdictions have adopted different variants of it. A recent survey on predatory pricing is found in Elzinga and Mills (2015).

In our paper, we abstracted from the debate on the limits and merits of the Areeda-Turner rule. We simply recognise its importance in the assessment of predatory pricing and focus instead on the extension of the rule to two-sided markets.

We first showed that a monopolist's price-cost margins in a two-sided market are interrelated. Furthermore, for a two-sided monopolist, even in the absence of actual or potential competition, it may be profit-maximizing to charge a price below marginal cost on one side of the market. As a result, the Areeda-Turner rule that the price is below average variable cost or marginal cost on one side of the market cannot be considered as a sign of predation in two-sided markets.

We then followed the Areeda-Turner logic to derive a corresponding rule for two-sided markets. We argued that one should apply the rule by taking into account revenues and costs from both sides of the market. Hence, in a two-sided market the rule should be rephrased as requiring that the weighted average of the prices, with the weights given by the marginal network effect, is below the weighted average of the marginal costs. As in a one-sided market, given the difficulty to measure marginal costs, for most practical purposes, courts should presume as unlawful a (weighted) price level that is below the (weighted) average variable cost level. The only partial exception to this rule is the particular case in which one of the two sides of the market is indifferent to the other side. In that case, to assess the predatory nature of prices on the side that exerts no externality on the other, a one-sided Areeda-Turner rule can be applied.

As applications, we analysed two alleged cases of predatory behaviour in the market for daily newspapers. The first case, the Times-Independent price war, concerns a two-sided market where customers on both sides pay for the product or

\footnotetext{
27 Recognizing that free newspapers also (bear a cost to) serve readers should imply the necessity of a definition of a relevant market on the readers' side. Interestingly, as shown in Filistrucchi et al. (2014), competition authorities generally fail to define a second relevant market on the side where the product is given away for free. The OFT in Aberdeen Journals is no exception.
} 
service that they receive. The Independent claimed that the cover prices of The Times were predatory because they were lower than the average variable cost of a copy of the newspaper. We showed that if one took into account the revenues from advertising, as suggested by a two-sided Areeda-Turner rule, the prices could not be presumed predatory. The Aberdeen Journals case illustrates how one should deal with those two-sided markets in which one side of the market does not pay, as the case concerned predation by a free daily newspaper. Correctly, the OFT took into account costs from both sides of the market (in addition to the price of advertising) when calculating profit margins.

Overall, the discussion of these cases highlights the importance of using the correct Areeda-Turner rule for two-sided markets rather than the traditional onesided rule.

Acknowledgments We would like to thank Pauline Affeldt, Enrico di Tomaso, Martin Duch, and Serena Nuzzi for their precious research assistance. We also thank Jan Boone, Stephen Martin and seminar participants at the workshop on the Areeda-Turner rule at the Tinbergen Institute for useful comments, and Cedric Argenton for pointing out to us the case Bottin Cartographes versus Google. We are grateful for financial support from the NET Institute, http://www.NETinst.org. Lapo Filistrucchi also acknowledges a Microsoft Grant to TILEC, which was provided in accordance with the KNAW Declaration of Scientific Independence. The views expressed here are not necessarily the ones of the Net Institute nor of the Microsoft Corporation.

Conflict of interest The authors declare that they have no conflict of interest.

Open Access This article is distributed under the terms of the Creative Commons Attribution 4.0 International License (http://creativecommons.org/licenses/by/4.0/), which permits unrestricted use, distribution, and reproduction in any medium, provided you give appropriate credit to the original author(s) and the source, provide a link to the Creative Commons license, and indicate if changes were made.

\section{References}

Affeldt, P., Filistrucchi, L., \& Klein, T. J. (2013). Upward pricing pressure in two-sided markets. The Economic Journal, 123(572), 505-523.

Areeda, P., \& Turner, D. (1975). Predatory pricing and related practices under Section 2 of the Sherman Act. Harvard Law Review, 88(4), 697-733.

Argentesi, E., \& Filistrucchi, L. (2007). Estimating market power in a two-sided market: The case of newspapers. The Journal of Applied Econometrics, 22(7), 1247-1266.

Armstrong, M. (2006). Competition in two-sided markets. RAND Journal of Economics, 37(3), 668-691.

Behringer, S., \& Filistrucchi, L. (2011). Price wars in two-sided markets: The case of the U.K. quality newspapers in the '90s. Mimeographed.

Caillaud, B., \& Jullien, B. (2001). Competing cybermediaries. European Economic Review, 45(4-6), 797-808.

Caillaud, B., \& Jullien, B. (2003). Chicken and egg: Competition among intermediation service providers. RAND Journal of Economics, 34(2), 309-328.

Elzinga, K. G., \& Mills, D. E. (2015). Predatory pricing. In R. D. Blair \& D. D. Sokol (Eds.), The Oxford Handbook of International Antitrust Economics (Vol. 2). Oxford: Oxford University Press.

Evans, D., \& Noel, M. (2008). The analysis of mergers that involve multisided platform businesses. Journal of Competition Law and Economics, 4(3), 663-695.

Evans, D. S. (2003). The antitrust economics of multi-sided platform markets. Yale Journal on Regulation, 20, 325-382. 
Evans, D. S., \& Schmalensee, R. (2015). The antitrust analysis of multi-sided platform businesses. In R. D. Blair \& D. D. Sokol (Eds.), The Oxford Handbook of International Antitrust Economics (Vol. 1). Oxford: Oxford University Press.

Fan, Y. (2013). Ownership consolidation and product characteristics: A study of the U.S. daily newspaper market. American Economic Review, 103(5), 1598-1628.

Filistrucchi, L., Geradin, D., \& van Damme, E. (2013). Identifying two-sided markets. World Competition, 36(1), 33-59.

Filistrucchi, L., Geradin, D., van Damme, E., \& Affeldt, P. (2014). Market definition in two-sided markets: Theory and practice. Journal of Competition Law and Economics, 10(2), 293-339.

Filistrucchi, L., \& Klein, T. (2013). Price competition in two-sided markets with heterogeneous consumers and network effects. Mimeographed.

Filistrucchi, L., Klein, T. J., \& Michielsen, T. (2012). Assessing unilateral merger effects in a two-sided market: An application to the Dutch daily newspaper market. Journal of Competition Law and Economics, 8(1), 1-33.

Fletcher, A. (2007). Predatory pricing in two-sided markets: A brief comment. Competition Policy International, 3(1), 221-224.

Kaiser, U., \& Song, M. (2009). Do media consumers really dislike advertising? An empirical assessment of the role of advertising in print media markets. International Journal of Industrial Organization, 27, 292-301.

Kaiser, U., \& Wright, J. (2006). Price structure in two-sided markets: Evidence from the magazine industry. International Journal of Industrial Organization, 24, 1-28.

Motta, M., \& Vasconcelos, H. (2012). Exclusionary pricing in a two-sided market. CEPR Discussion Papers 9164, C.E.P.R. Discussion Papers.

Parker, G. G., \& van Alstyne, M. W. (2005). Two-sided network effects: A theory of information product design. Management Science, 51(10), 1494-1504.

Rochet, J. C., \& Tirole, J. (2002). Cooperation among competitors: Some economics of payment card associations. RAND Journal of Economics, 33(4), 549-570.

Rochet, J. C., \& Tirole, J. (2003). Platform competition in two-sided markets. Journal of the European Economic Association, 1(4), 990-1029.

Rochet, J. C., \& Tirole, J. (2006). Two-sided markets: A progress report. RAND Journal of Economics, 37(3), 645-667.

Weyl, G. (2010). A price theory of multi-sided platforms. American Economic Review, 100(4), $1642-1672$.

Wright, J. (2004). One-sided logic in two-sided markets. Review of Network Economics, 3(1), 44-64. 